\title{
Cloning, Expression and Purification of Arylsulfate Sulfotransferase from Eubacterium A-44
}

\author{
Bomi KIm, ${ }^{a}$ Yang-Jin Hyun, ${ }^{a}$ Keun-Sook LeE, ${ }^{a}$ Kyoichi KoBashi, ${ }^{b}$ and Dong-Hyun KIM ${ }^{*, a}$ \\ ${ }^{a}$ College of Pharmacy, Kyung Hee University; 1, Hoegi, Dongdaemun-ku, Seoul 130-701, Korea: and ${ }^{b}$ Toyama New \\ Industry Organization; 529, Takata, Toyama 930-0866, Japan. \\ Received June 19, 2006; accepted September 27, 2006
}

\begin{abstract}
A gene (astA) encoding arylsulfate sulfotransferase (ASST), which transfers a sulfate group from phenolic sulfate esters to phenolic acceptors, was cloned from a Eubacterium A-44 genomic library. The probe (1.5 kb fragment) for the astA gene was prepared from the PCR product of the primers produced using two internal amino acid sequences of ASST, which had been purified from Eubacterium A-44. The astA gene was cloned into the pKF3vector. Its sequence revealed a 1863 bp open reading frame (ORF) encoding a protein containing 620 amino acids with a secretary signal peptide, and showed $91 \%$ homology (identity) to Eubacterium rectale IIIH previously reported. The cloned ast $A$ gene was expressed under the $T 7$ promoter of the expression vectors, pET$39 \mathrm{~b}(+)$ and pET-26b(+), in Escherichia coli BL21 (DE3), and the expressed ASSTs were purified using His Bind column chromatography. The specific activities of the purified ASSTs were $25.6 \mu \mathrm{mol} / \mathrm{min} / \mathrm{mg}$ and $37.1 \mu \mathrm{mol} / \mathrm{min} / \mathrm{mg}$, respectively.
\end{abstract}

Key words arylsulfate sulfotransferase; Eubacterium A-44; astA gene; gene cloning

Arylsulfate sulfotransferase (ASST) was purified from $E u$ bacterium A-44, ${ }^{1,2}$ which is an anaerobe from the human intestinal microflora that metabolizes picosulfate sodium. ${ }^{3)}$ ASST catalyzes the transfer of a sulfate group from various phenyl sulfate esters to phenolic acceptor substrates. Although Goldberg et al. cloned the ASST gene (astA) from Eubacterium rectale IIIH, the physiological action of ASST is not completely understood. ${ }^{4)}$ Nevertheless, the enzyme has potential use in the in vitro O-sulfation of peptide hormones that require the sulfoconjugation of a hydroxyl group from tyrosine for their biological activity, such as cholecystokinin and hirudin. 5 )

In this study, the astA gene encoding ASST of Eubacterium A-44 was cloned and compared with the previously reported recombinant ASST in order to determine its use industrially. The cloned astA was expressed in Escherichia coli, and its substrate specificity from the purified recombinant clones was determined.

\section{MATERIALS AND METHODS}

Construction of Eubacterium A-44 Genomic Library The following sequence was used to clone the astA gene of Eubacterium A-44. First, ASST was purified according to previously reported methods, ${ }^{1)}$ and two internal amino acid peptides, AST 16-1 (5'-ACRGCRGARACRGGRTARCA-3') and AST 16-2 (5'-CGRTARTARTTNCCNGGNACRTG-3') that were obtained by trypsin digestion were sequenced. The two primers were synthesized according to their sequences and PCR was performed. The PCR product was labeled with DIG and used as a hybridization probe. In order to prepare the genomic library of Eubacterium A-44, the chromosomal DNA was partially digested with HindIII at $37^{\circ} \mathrm{C}$ for $2 \mathrm{~h}$ and size-fractionated on a $0.5 \%$ TAE agarose gel. A portion of the digested chromosomal fragments $(2-3 \mathrm{~kb})$ was removed from the gel. The DNA was extracted and ligated to the pKF3 vector (Takara, U.S.A.), which was digested with the same enzyme, and transformed into $E$. coli $\mathrm{TH} 2$ competent cells (Takara, U.S.A.). The positive clones were screened.
Southern blotting and DNA sequencing were used to confirm the cloned ASST gene.

Expression and purification of Eubacterium A-44 ASST In order to express the astA gene, four primers for the full length of ASST, which contain a signal peptide or/and stop codon, were synthesized and amplified by PCR. Two 5' primers (BM-A44-F1 and BM-A44-F2) contained a common unique BamHI site: BM-A44-F1 (5'-GAGAGAGGATCCNATGTCAGTAAAATA-3') has a signal peptide but BMA44-F2 (5'-GAGAGAGGATCCNGAAGCAGAGCA-3') does not. Two $3^{\prime}$ primers (BM-A44-R1 and BM-A44-R2) have a common unique HindIII site: BM-A44-R1 (5'GAGAGAAAGCTTGCAGCTGATCGTA-3') does not have a stop codon whereas BM-A44-R2 (5'-GAGAGAAAGCTTTTAGCAGCTGATCGTA-3') does. Each PCR product, which contained a BamHI site at the $5^{\prime}$ ends and a HindIII site at the $3^{\prime}$ ends, was subcloned into the pGEM-T easy vector (Promega, U.S.A.), and transformed into the E. coli JM109 competent cells (Promega, U.S.A.). The recombinant plasmid was isolated using a plasmid SV kit (Generalbio, Korea), purified from $0.8 \%$ agarose gel and ligated into the pET-39b $(+)$ and pET-26b(+) expression vectors (Novagen, U.S.A.), which contained the inducible $\mathrm{T} 7$ promoter. Both $\mathrm{pET}-39 \mathrm{~b}(+)$ and $\mathrm{pET}-26 \mathrm{~b}(+)$ were used for the purpose of enhancing the solubility. The pET-39b $(+)$ vector contains DsbA, which is the periplasmic enzyme that catalyzes the formation and isomerization of the disulfide bond. The $\mathrm{pET}$ $26 \mathrm{~b}(+)$ vector contains an N-terminal pelB signal sequence for potential periplasmic localization. The PCR products were ligated into the pET-39b $(+)$ vector containing the 6 His tag backward or forward using the primer with the stop codon, and in the pET-26b(+) vector with the 6 His tag only backward using the stop codon-excluded primer (Fig. 1). The ligated plasmids were transformed into the expression host, E. coli BL21 (DE3), which was confirmed by restriction enzyme analysis.

The ASST expressed in astA-cloned E. coli was purified by culturing the bacteria to the mid-log phase $\left(\mathrm{OD}_{600} 0.6-1\right)$ in $100 \mathrm{ml}$ of LB broth containing $30 \mu \mathrm{g} / \mathrm{ml}$ of kanamycin. 
(1) astA insertion with signal peptide in $\mathrm{pET}-39 \mathrm{~b}(+)$ vector

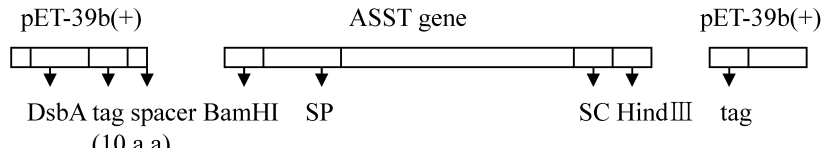

(2) astA insertion without signal peptide in pET-39b(+)

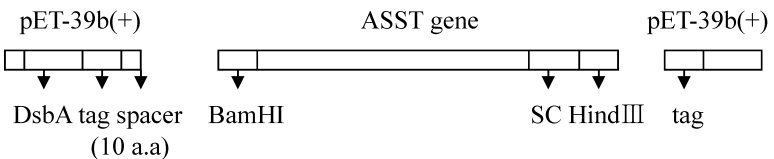

(3) astA insertion with signal peptide in $\mathrm{pET}-26 \mathrm{~b}(+)$

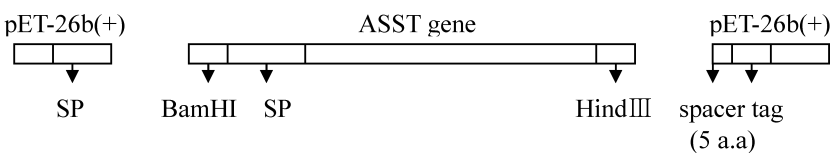

(4) astA insertion without signal peptide in pET-26b(+) vector (5 a.a)

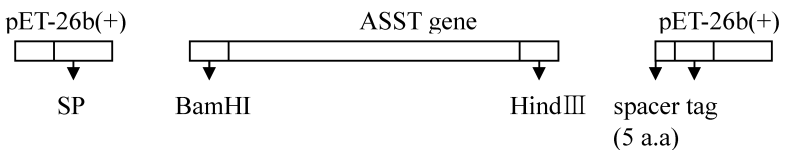

Fig. 1. Ligation Maps of the Arylsulfate Sulfotransferase Gene and Expression Vectors

(1) and (2) were ligated in the pET $39 \mathrm{~b}(+)$ vector. (3) and (4) were ligated in the pET $26 \mathrm{~b}(+)$ vector. $(2)$ and (4) contained the vector signal peptide (without the signal peptide of astA). The pET vector contains the backward 6 His-tag $(\operatorname{tag})$ and the $39 \mathrm{~b}(+)$ vector contains the forward 6 His tag. SP means a signal peptide, SC indicates a stop codon and the tag is 6 His-tag.

The cells were then induced with $1 \mathrm{mM}$ IPTG at $20^{\circ} \mathrm{C}$ for $16 \mathrm{~h}$. The cultured cells were centrifuged at $10000 \times \boldsymbol{g}$ for $10 \mathrm{~min}$ at $4{ }^{\circ} \mathrm{C}$, resuspended in $10 \mathrm{ml}$ of an ice-cold $1 \times$ binding buffer $[20 \mathrm{~mm}$ Tris $-\mathrm{HCl}(\mathrm{pH} 7.9)$ containing $500 \mathrm{~mm}$ $\mathrm{NaCl}$ and $5 \mathrm{~mm}$ imidazole, Novagen, U.S.A.], sonicated at 4 ${ }^{\circ} \mathrm{C}$ and centrifuged at $14000 \times \boldsymbol{g}$ for $20 \mathrm{~min}$. The resulting supernatant was applied to the His Bind column (Novagen, U.S.A.), washed stepwise with a $1 \times$ binding and $1 \times$ wash buffer $[20 \mathrm{~mm}$ Tris- $\mathrm{HCl}$ (pH 7.9) containing $500 \mathrm{~mm} \mathrm{NaCl}$ and $60 \mathrm{~mm}$ imidazole, Novagen, U.S.A.] and eluted with a $1 \times$ elution buffer $[20 \mathrm{~mm}$ Tris- $\mathrm{HCl}(\mathrm{pH} 7.9)$ containing $0.5 \mathrm{~m}$ $\mathrm{NaCl}$ and $1 \mathrm{M}$ imidazole, Novagen, U.S.A.].

The ASST expressed in the pET-39b $(+)$ vector was dialyzed the eluate against the $20 \mathrm{~mm}$ Tris- $\mathrm{HCl}$ buffer $(\mathrm{pH} 7.4)$ containing $50 \mathrm{~mm} \mathrm{NaCl}$ and $2 \mathrm{mM} \mathrm{CaCl}_{2}$. The dialyzed solution was incubated with the recombinant enterokinase (Novagen, U.S.A.) at $20^{\circ} \mathrm{C}$ for $3 \mathrm{~h}$. The cleaved protein mixture was then added to the His Bind Column, and eluted with a $1 \times$ binding buffer. SDS-PAGE analysis confirmed that the ASST of the eluted fractions was a homogenous protein with the fusion segment (DsbA) completely removed.

Determination of Protein The quantity of the protein was determined using the Bradford method. ${ }^{\text {) }}$

Assay of ASST Activity The reaction mixture (total volume of $0.63 \mathrm{ml}$ ) used for the ASST activity assay contained $30 \mu \mathrm{l}$ of $50 \mathrm{~mm} p$-nitrophenyl sulfate (PNS), $0.29 \mathrm{ml}$ of $20 \mathrm{~mm}$ tyramine (occasionally other acceptors at the indicated concentration), $0.21 \mathrm{ml}$ of $0.1 \mathrm{~m}$ Tris- $\mathrm{HCl}$ buffer, $\mathrm{pH}$ 8.0 , and $0.1 \mathrm{ml}$ of the enzyme solution. The reaction mixture was incubated at $37^{\circ} \mathrm{C}$ for $5 \mathrm{~min}$, and quenched by adding 1 $\mathrm{N} \mathrm{NaOH}(0.4 \mathrm{ml})$. The absorbance at $405 \mathrm{~nm}$ was measured. ${ }^{6}$

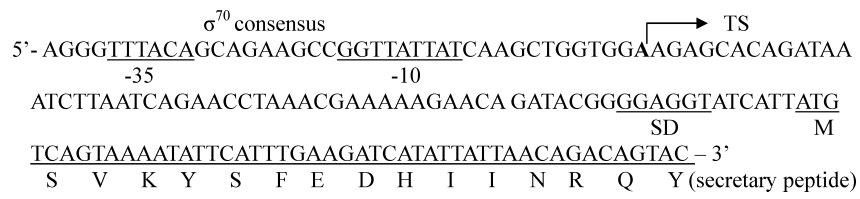

Fig. 2. Nucleotide Sequence of the Eubacterium A-44 astA Gene Regulation Region

The 5'-ends of the Eubacterium A-44 ASST mRNA (transcriptional start site of ASST gene) is indicated in boldface (A) with the dextral arrow (TS) in the DNA sequence. The proposed Shine-Dalgarno (SD) sequence and the consensus sequence for the sigma 70-type promoter are underlined.

\section{RESULTS AND DISCUSSION}

The Eubacterium A-44 chromosomal DNA was partially digested with HindIII, ligated to the HindIII arms of the pKF3 vector and transformed $E$. coli TH2 competent cells. Two positive colonies were obtained using the DIG-detection method with the probe $(1.5 \mathrm{~kb})$ being prepared by PCR of the two primers synthesized according to the internal amino acid sequences (the sequences were H-V-P-G-N-Y-Y-R and T-AE-T-G-Y-H). The colonies were identified from the libraries (the 75th recombinant plasmid). The inserted DNA (about $2 \mathrm{~kb}$ ), which was identified from the positive clones, was similar in size to the fragment previously prepared from the HindIII digested DNA. The inserted DNA was sequenced and analyzed using the GenBank homology search Blast system, and the ORF finder program in the NCBI and genecutter program. The Eubacterium A-44 astA gene consists of a $1863 \mathrm{bp}$ sequence encoding a protein with 620 amino acid residues containing a signal peptide (16 amino acids). The putative ribosome-binding site (Shine-Dalgarno sequence, GGAGGT) was located $7 \mathrm{bp}$ upstream from the start codon (ATG). ${ }^{7)}$ A sequence of the transcriptional start region of the A-44 astA gene was located 65 nucleotides upstream from the translational start codon (AUG) of ASST, and the putative sigma 70 type promoter sequences of both TTTACA (resembling -35 sequence) and GGTTATTAT (resembling -10 sequence) were located at positions -95 and -77 , respectively. ${ }^{8)}$ The three sequences related to Eubacterium A-44 were obtained from database searches of GenBank using BLAST2. The sequence of the A-44 astA gene was compared with the ASSTs from Eubacterium rectale IIIH, Klebsiella $\mathrm{K}-36^{9)}$ and Enterobacter AR-37. ${ }^{10)}$ The gene of Eubacterium rectale showed $91 \%$ homology to the Eubacterium A44 but the other astA genes did not. The amino acid sequence of the A-44 astA amino acid was compared with the ASSTs from Eubacterium rectale $\mathrm{IIIH}$, Klebsiella $\mathrm{K}-36^{9)}$ and Enterobacter AR-37. ${ }^{10}$ These three amino acids showed $96 \%, 23 \%$ and $22 \%$ (positives 98\%, 38\%, 39\%) homology (identity) to the Eubacterium A-44, respectively. (Fig. 3). The nucleotide sequence of the Eubacterium A-44 astA gene was deposited in GenBank (accession number, DQ683024).

In order to investigate the industrial applications of the recombinant astA gene in E. coli, astA was expressed by inserting the cloned gene with and without the codon of its signal peptide into the BamHI and HindIII sites of pET-39b(+) and $\mathrm{pET}-26 \mathrm{~b}(+)$ vector, which has a 6 His-tag. The inserted vectors were then transformed into the expression host $E$. coli BL21(DE3), cultured, and induced with $1 \mathrm{~mm}$ IPTG at $20^{\circ} \mathrm{C}$ for $16 \mathrm{~h}$. The cultured cells were collected by centrifu- 
$\begin{array}{ll}\text { E.amn } & \text { MFHPYRKTLLSGTVALALGLFATGA I AAGFQPAQPAGKLGA IVVDPYGNAPLTALIELDS } \\ \text { K. K36 } & \text { MFDKYRKTLVAGTVA I TLGLSASGVMAAGFKPAPPAGQLGAVIVDPYGNAPLTALVDLDS } \\ \text { E.A-44 } & \text {---MSVKYSFEDHI I NRQYEAEQAMLAKFEAGNYT I ANPLVTYNAYLVNPLSAVVCFNT } \\ \text { E.rec } & \text {---MSVKYSFEDHI VNRQYEAEQEMLKEFEAGNYT I ANPLVKYNAYLVNPLSAVVCFHT }\end{array}$

E.amn HTISDVKVTVHGKGEKGVPVSYSVGKQSLATYDGIPVFGLYQKHANKVTVEYTENGKAMK

K. K36

E.A-44

E.rec HVI SDVKVTVHGGKGEKGVE I SYPVGOESL KTYDGVP IFGL YOKFANKVTVEWKENGKVMK EKETAVTVTVLGKTPQGN I SHTFP----KAKKHVLP IVGLYSDYYNR IE IRAYRGESN I I EKETA I TVTVLGKTPQGN I SHTFP----KAKKHVLP I VGLYSDYQNRVE IRAYRGESN I I

EDYVIQTSA IVNRYMDNRSI SDLQKTKVI KVAPGFEDRLYLVVNTH--TFTPQGAEFHWHG DDYVVHTSAIVNNYMDNRSISDLQQTKVIKVAPGFEDRLYLVNTH--TFTAQGSDLHWHG TIOVPDVFDGKEVIYSMDTTPEYLQDNI ILVSPAGEDLAVGFDYAGDARWHMTVPCVFDV TI DVPDVFDGKEV I YSMDTTPEYLQDN I ILVSPAGEDLAVGFDYAGDARWHMT I PCVFDV

EKDKNAGLLDAGPAAGALPFDI APFTFVVDT-----EGEYRWWLDQDTFYDGHDMN I NKR EKDKNAGI LDAGPATGALPFD I APFTF I VDT--_---EGEYRUWLDQDTFYDGRDRD I NKP KRLKNGNL I MGSHRV I QMPYYMSGLYEI SPCGK I YKEFRLPGGYHHDEFEMEDGNLLSLT KRLKNGNL I MGSHRV I QMPYYMSGLY I I SPCGK I YKEFRLPGGYHHDEFEMEDGNLLSLT

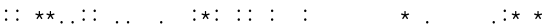

GYLMGIRETPRGTFTAVQGQHWYEFDMMGQVLADHKLPRGFLDATHESIETVNGTVLLRV GYLMG I RETPRGTFTAVQGQHWYEFDMMGQVLEDHKLPRGFADATHESIETPNGTVLLRV DDLTSETVEDMCVL I DRNTGE I LKTWDYKKFLDPKTVSRSGSWSDHDWFHNNAVWYDKNT DDLTSETVEDMCVL I DRNTGE I LKTWDYKKFLDPKKVSKSGSWSDHDWFHNNAVWYOKNT * $\quad \therefore \quad: \quad: \quad: * \quad::: \quad: *: \quad:$

GKRNYRKEDGLHVHT IRDQI IEVDKSGRV I DVWDLTK---I LDPLRDSLLGALDAGAVCV GKSNYRRDDGVHVTT I RDHI LEVDKSGRVVDVWDLTK---ILDPKRDALLGALDAGAVCV NSLTFSGRHI DSI VN I DYETGDLNWI I GDPEGWPEEMQKYFFKPVVGNNFGWQYEQHACV I NSLTFSGRH I DSMVN I DYETGELNWI I GDPEGWPEEMQKYFFKPVGNNFGWQYEQHACV I

N-------VDLEHAG---QQAKLEPDTPFGDALGVGAERNWAHVNPI AYDAKDDAI ILSS N------VDLAHAG---QQAKLEPDTPFGDALGVGPGRNWAHVNSI AYDAKDDSI I LSS TPDGDVMCFDNHHHYGSKNKENYLAAKDNYSRGVRYKI NTDDMTIEQVWWYGKDRGAEFFS TPDGDVMCFDNHHYGSKNPEKYLAARDNYSRGVRYK I NTDDMT I EQVWQYGKDRGAEFFS

RHQG I VKI GSDKKVKWILAPAKGWNKQLASKLLKPVDSKGNPLTCNENGKCENTDFDFSY RHQGVVK I GRDKQVVW ILAPSKGWEKPLASKLLKPVDANGKP I TCNENGLCENSDFDFTY PYI CNVQYYNEGHYMVHSGG I AYDSEGNPSEALGAFAKDQGGRLES I TVE I CDNKKMLDL PY I CNVEYYNEGHYMVHSGG I AYDTEGNPSEALGAFAKDQGGRLES I TVE I CDNKKMLDL

$$
\star::: \quad: \quad * \text { * } \quad:
$$

TQHTAWLTDKGTLTVFDNGDGRWLEQPALPSMKYSRFVEYK I DEKNGTVQPLWQYGKERG TQHTAW I SSKGTLT I FDNGDGRHLEQPALPTMKYSRFVEYK I DEKKGTVQQVWEYGKERG HVPGNYYRGEKLKLYSDG I NLELGKGQ I LGEMGVTKEFDTE I PLD-PSGEMLPESCNAR I HVPGNYYRGEKLLKLYSDG I NLELGKGQILGEMGVTKEFDTE I PLE-PSGEMLPESCNAR I

YDFYSP I TSVIEYQKDRDT IFGFSG-----SI INLFEVGQPT I GK INE I DYKTKDVKVE ID YDFYSP I TSI IEYQADRNTMFGFGG-----SIHLFDVGQPTVGKLNE I OYKTKEVKVE ID EDE I DRFTFFSRFEKGQLVMLLLEQGEEVHRYF I STTAVPFLAMCCGTFLDSDDRNTRTN EDE I DRFTFFSRFEKGQLVMLLLEQGEEVHRYF I STTAVPFLAMCCGTFLDSDDRNTRTN

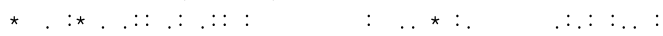

VLSDKPNQTHYRALLVHPQQMF-------

VLSDKPNQTHYRALLVRPQQMFK

I NKAGLKGTYDVRVI I DDKKYETGVT ISC

I NKTGLKGTYDLRVI I DDKKYETGVT ISC

Fig. 3. CLUSTAL W Multiple Sequence Alignment of the ASST from Eubacterium A-44 (E.A-44) with the ASST from Eubacterium rectale IIIH (E.rec) and Enterobacter amnigenus AR-37 (E.amn) and Klebsiella K-36 (K.K36)

The asterisks below the aligned sequences indicate the same amino acids in all four sequences. The positions with colons below contain a strongly conserved residue, and the periods indicate more weakly conserved residues. The gaps introduced to align the protein sequences optimally are indicated by dashes.

gation and their ASST activity was measured (Table 1). The proteins were well expressed by the astA gene with the codon of its signal peptide and ASST activity that was independent of the DsbA was observed. On the other hand, although the astA gene without the codon of its signal peptide was expressed, no ASST activity was observed. These results
Table 1. Arylsulfate Sulfotransferase Activity of Eubacterium A-44 and the Recombinant E. coli Strains

\begin{tabular}{ll}
\hline \hline \multicolumn{1}{c}{ Strain } & $\begin{array}{c}\text { Activity } \\
(\mathrm{U} / \mathrm{mg})\end{array}$ \\
\hline Eubacterium A-44 & 0.1 \\
E. coli BL21(DE3)-pET-39b(+) with astA signal peptide & 1.4 \\
E. coli BL21(DE3)-pET-39b(+) without astA signal peptide & 0 \\
E. coli BL21(DE3)-pET-26b(+) with astA signal peptide & 2.5 \\
E. coli BL21(DE3)-pET-26b(+) without astA signal peptide & 0 \\
\hline
\end{tabular}

(A)

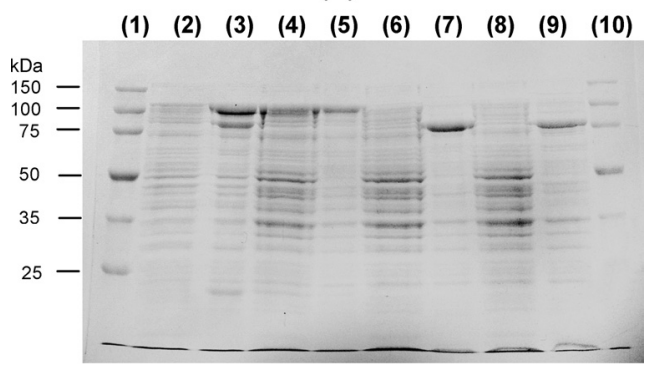

(B)

(C)
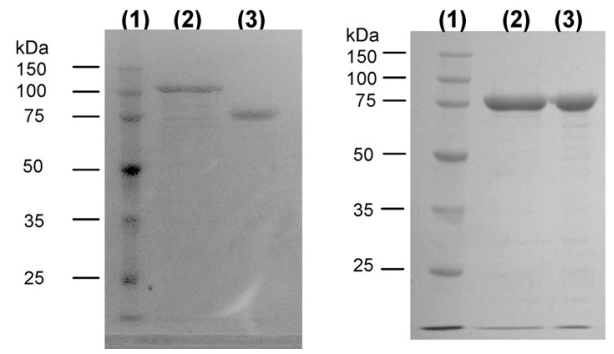

Fig. 4. Sodium Dodecyl Sulfate-Polyacryamide Electrophoresis of Arylsulfate Sulfotransferase (ASST) Expressed and Purified in astA-Cloned E. coli BL21(DE3)

(A) ASST expressed in the astA-cloned E. coli BL21(DE3). The astA gene with (3) or without the signal peptide (5) inserted in the pET-39b(+) or with (7) or without the signal peptide (9) in the pET-26b(+) was transformed into the E. coli BL21(DE3), induced with $1 \mathrm{~mm} \mathrm{IPTG}$ at $20^{\circ} \mathrm{C}$ for $16 \mathrm{~h}$, collected at $5000 \times \mathrm{g}$ for $20 \mathrm{~min}$ and examined by SDS-PAGE. (2), (4), (6) and (8) were carried out using the same methods reported for (3), (5), (7) and (9) without the IPTG treatment, respectively. (1) and (10) indicate the molecular markers. (B) ASST was purified from the astA gene-inserted pET$39 \mathrm{~b}(+)$ cloned E. coli BL21(DE3). The expressed ASST was purified using His Bind column chromatography (2), and treated with enterokinase, and then separated by His Bind column chromatography (3). (1) indicates the molecular markers. (C) ASST purified from the astA gene-inserted pET-26b(+) cloned E. coli BL21(DE3). The expressed ASST was purified using His Bind column chromatography (2), dialyzed and rechromatographed on a His Bind column chromatography (3). (1) indicates the molecular markers.

suggest that the signal peptide itself is not essential for protein expression but is important for the enzyme activity of the astA gene.

The ASST expressed in E. coli BL21(DE3) was collected by centrifugation, sonicated, and then centrifuged again. The resulting supernatant was purified by His Bind column chromatography, and the eluted ASST expressed in pET $39 \mathrm{~b}(+)$ vector was treated with enterokinase to exclude the DsbA and chromatographed on a His Bind column. Before the enterokinase treatment, the molecular weight of the ASST expressed with the pET-39b(+) and pET-26b(+) vectors was determined to be $100 \mathrm{kDa}$ and $75 \mathrm{kDa}$. After the enterokinase treatment, the DsbA forward (approximately $25 \mathrm{kDa}$ ) of ASST expressed in the pET-39b(+) vector was cleaved. SDS-PAGE showed that the molecular weight of the cleaved 
Table 2. Purification of the Arylsulate Sulfotransferase Expressed from astA Gene Cloned E. coli BL21(DE3)

\begin{tabular}{|c|c|c|c|c|}
\hline Stage & Activity $(\mu \mathrm{mol} / \mathrm{min})$ & Protein $(\mathrm{mg})$ & Specific activity $(\mu \mathrm{mol} / \mathrm{min} / \mathrm{mg})$ & Yield (\%) \\
\hline \multicolumn{5}{|c|}{ in $E$. coli BL21(DE3)-pET-39b(+) } \\
\hline 1. Crude extract & 32 & 22 & 1.5 & 100 \\
\hline 2. His-Bind column I & 31.2 & 1.4 & 22.3 & 107 \\
\hline 3. Enterokinase & 20.5 & 0.8 & 25.6 & 64.0 \\
\hline \multicolumn{5}{|c|}{ in $E$. coli BL21(DE3)-pET-26b(+) } \\
\hline 1. Crude extract & 35 & 14 & 2.5 & 100 \\
\hline 2. His-Bind column I & 28.6 & 0.8 & 35.8 & 81.7 \\
\hline 3. His-Bind column II & 26.0 & 0.7 & 37.1 & 74.3 \\
\hline
\end{tabular}

ASST was approximately $75 \mathrm{kDa}$ (Fig. 4). The specific activity of the purified enzyme expressed with the pET-39b(+) and $\mathrm{pET}-26 \mathrm{~b}(+)$ vectors were $25.6 \mu \mathrm{mol} / \mathrm{min} / \mathrm{mg}$ and 37.1 $\mu \mathrm{mol} / \mathrm{min} / \mathrm{mg}$ (Table 2 ). The specific activity of these purified ASSTs was low compared with that of the previously reported Eubacterium A-44. ${ }^{4}$ In order to determine the significance of this observation, the effect of $\mathrm{Ni}^{2+}$ on the ASST activity was investigated. $\mathrm{Ni}^{2+}$ inhibited the enzyme but the inactivated enzyme activity was not reactivated by dialysis. These results suggest that the low specificity activity of the recombinant ASST may be due to the difference of ASST activity assay between the present and previous reports ${ }^{1,4)}$ or the inactivation of the overexpressed ASST by unknown factors.

The acceptor substrate specificity of the ASSTs purified from the cloned E. coli was investigated (Table 3). Among the substrates tested, tyramine was the best acceptor substrate of the cloned ASSTs, followed by tyrosine and 4-hydroxybenzoic acid. Their substrate specificity was similar to that of the ASST purified from Eubacterium A-44. ${ }^{2}$ )

Overall, it is believed that the expressed ASST can be applied on an industrial scale to areas such as the sulfation of peptides.

\section{REFERENCES}

1) Kobashi K., Kim D. H., Morikawa T., J. Protein Chem., 6, 237-244 (1987).
Table 3. Acceptor Substrate Specific Activity of Arylsulate Sulfotransferases Expressed in astA Cloned E. coli BL21(DE3)

\begin{tabular}{lccc}
\hline \hline & \multicolumn{3}{c}{ Relative activity $^{\mathrm{a}}(\%)$} \\
\cline { 2 - 4 } & $\mathrm{pET}-39 \mathrm{~b}(+)$ & $\mathrm{pET}-26 \mathrm{~b}(+)$ & $\mathrm{A}-44$ \\
\hline Tyramine & 100 & 100 & 100 \\
4-Hydroxy benzoic acid & 3.6 & 4.3 & 2.3 \\
Tyrosine & 8.7 & 7.1 & 2.8 \\
\hline
\end{tabular}

The specific activities of the purified enzymes, ASSTs inserted and expressed and purified in pET-39b(+) and in pET-26b(+) and purified A-44 for tyramine + PNS were $22.1,37.1$ and $75.5 \mu \mathrm{mol} / \mathrm{min} / \mathrm{mg}$, respectively, which are shown as $100 \%$, respectively.

2) Kim D. H., Konishi L., Kobashi K., Biochim. Biophys. Acta, 872, 33 41 (1986).

3) Kobashi K., Fukaya Y., Kim D. H., Akao T., Takebe S., Arch. Biochem. Biophys., 245, 537-539 (1986).

4) Goldberg S. L., Nanduri V., Cino P. M., Patel R., J. Ind. Microbiol. Biotechnol., 25, 306-309 (2000).

5) Konishi-Imamura L., Sato M., Dohi K., Kadota S., Namba T., Kobashi K., Biol. Pharm. Bull., 17, 1018-1022 (1994).

6) Bradford M., Anal. Chem., 2006, 155-157 (2006).

7) Shine J., Dalgarno L., Proc. Natl. Acad. Sci. U.S.A., 71, 1342-1346 (1974).

8) Miyata T., Kashige N., Satho T., Yamaguchi T., Aso Y., Miake F., Curr Microbiol., 51, 105-109 (2005).

9) Baek M. C., Kim S. K., Kim D. H., Kim B. K., Choi E. C., Microbiol. Immunol., 40, 531-537 (1996).

10) Kwon A. R., Oh T. G., Kim D. H., Choi E. C., Protein Expr. Purif., 17, $366-372$ (1999). 